\title{
MASCC Multidisciplinary Evidence-Based Recommendations for the Management of Malignant Bowel Obstruction in Advanced Cancer
}

\author{
Ainhoa Madariaga ( $\nabla$ ainhoama@hotmail.com ) \\ 12th of October University Hospital: Hospital Universitario 12 de Octubre https://orcid.org/0000-0001- \\ 7166-9762
}

Jenny Lau

Princess Margaret Hospital: Princess Margaret Hospital Cancer Centre

Arunangshu Ghoshal

Princess Margaret Hospital: Princess Margaret Hospital Cancer Centre

Tomasz Dzierżanowski

Medical University of Warsaw: Warszawski Uniwersytet Medyczny

Philip Larkin

University of Lausanne: Universite de Lausanne

Jacek Sobocki

Postgraduate Medical Education

\section{Andrew Dickman}

Royal Liverpool \& Broadgreen Hospitals NHS Trust: Liverpool University Hospitals NHS Foundation Trust

Kate Furness

Swinburne University of Technology

Rouhi Fazelzad

University Health Network

Gregory B Crawford

Northern Adelaide Local Health Network

Stephanie Lheureux

Princess Margaret Hospital Cancer Centre

\section{Research Article}

Keywords: Malignant bowel obstruction, Palliative Care, Cancer - Gastrointestinal, Gynecologic Neoplasm, Guidelines

Posted Date: December 28th, 2021 
DOI: https://doi.org/10.21203/rs.3.rs-1077646/v1

License: (c) (1) This work is licensed under a Creative Commons Attribution 4.0 International License. Read Full License

Version of Record: A version of this preprint was published at Supportive Care in Cancer on March 10th, 2022. See the published version at https://doi.org/10.1007/s00520-022-06889-8. 


\section{Abstract}

\section{Purpose}

To provide evidence based recommendations on the management of malignant bowel obstruction (MBO) for patients with advanced cancer.

\section{Methods}

The Multinational Association for Supportive Care in Cancer (MASCC) MBO study group conducted a systematic review of databases (inception to March 2021) to identify studies about patients with advanced cancer and MBO that reported on the following outcomes: symptom management, bowel obstruction resolution, prognosis, overall survival and quality of life. The review was restricted to studies published in English but no restrictions were placed on publication year, country and study type. As per the MASCC Guidelines Policy, the findings were synthesized to determine the levels of evidence to support each MBO intervention and, ultimately, the graded recommendations and suggestions.

\section{Results}

The systematic review identified 17,656 published studies and 397 selected for the guidelines. The MASCC study group developed a total of 25 evidence-based suggestions and recommendations about management of MBO-related nausea and vomiting, bowel movements, pain, inflammation, bowel decompression and nutrition. Expert consensus-based guidance about advanced care planning and psychosocial support is also provided.

\section{Conclusion}

This MASCC guideline provides comprehensive, evidence-based recommendations about MBO management for patients with advanced cancer.

\section{Introduction}

Malignant bowel obstruction (MBO) is a severe complication in advanced cancer. ${ }^{1} \mathrm{MBO}$ was defined in the International Conference on MBO and Clinical Protocol Committee as: i) clinical evidence of bowel obstruction (via history, physical and/or radiological examination), ii) bowel obstruction beyond the ligament of Treitz, iii) diagnosis of intra-abdominal cancer with incurable disease, or a non-intraabdominal primary cancer with clear intraperitoneal disease. ${ }^{1}$ The algorithm of care for patients with MBO is not uniform and often differs according to clinical factors (e.g., prognosis) and between institutions and countries.

In this article, the Multinational Association for Supportive Care in Cancer (MASCC) MBO multidisciplinary study group presents comprehensive, evidence-based recommendations about MBO 
management for patients with advanced cancer and the methodology used to develop these recommendations.

\section{Background}

\section{Etiology}

MBO most frequently occurs when patients have advanced cancers that originate in the abdomen or pelvis. Though the incidence of MBO is not well established, based on retrospective and autopsy-based studies, MBO is estimated to occur in $10-28 \%$ of patients with gastrointestinal cancers and up to $51 \%$ of patients with ovarian cancer. ${ }^{2}$ Limitations of these estimates include patient population selection and non-homogeneous criteria to diagnose MBO.

The mechanisms of MBO are multi-factorial and can be divided into two main groups: mechanical and functional obstruction. ${ }^{2,3}$ Causes of mechanical obstruction include extrinsic obstruction of the lumen by pathology, such as mesenteric and omental masses, adhesions and fibrosis; intra-luminal obstruction from tumour growth in the bowel; and intra-mural obstruction by tumour within the bowel wall which impairs motility. Whereas, functional obstruction is a result of motility disorders, which can be due to tumour infiltration of mesentery, nerves and/or celiac and enteric plexus, and paraneoplastic syndromes. Further, non-malignant factors may induce or worsen bowel obstruction (BO) in patients with advanced cancer, including constipation/fecal impaction, pharmacological (i.e., opioids, intra-peritoneal chemotherapy), fibrosis and adhesions from prior surgery and radiotherapy.

\section{Pathophysiology and symptoms}

MBO can occur in the small or large bowel, with small BO being more common. ${ }^{3,4}$ The obstruction can be partial or complete, and can occur at single or multiple transition points. MBO causes reduction or absence of movements of the intestinal content and bowel distension. ${ }^{3,4}$ The accumulation of content in the intestinal lumen increases the epithelial surface area and prompts an accumulation of gastric, pancreatic, biliary secretions, water and salt, which damages the intestinal epithelium and triggers an inflammatory response with intestinal edema, hyperemia, and production of inflammatory mediators (i.e., prostaglandins, vasoactive intestinal polypeptide, nociceptive mediators). Bacterial overgrowth and translocation are important mechanisms in development of symptoms. The cumulative impact of these events result in abdominal pain, cramps, distention, nausea, vomiting, absence of gas and stool passage and, occasionally, overflow diarrhea. MBO symptoms usually start gradually and become more frequent and severe when a complete obstruction occurs. Re-obstruction and malnutrition are common with malnutrition being an independent predictor of poor survival in this population. ${ }^{5-8}$ 


\section{Diagnosis}

$\mathrm{MBO}$ is a clinical diagnosis that is confirmed with radiological imaging. Historically, abdominal $\mathrm{x}$-rays were recommended to be the initial imaging modality but their sensitivity to detect MBO is moderate and poses challenges in detecting the exact site, cause or complications derived from $\mathrm{MBO} .{ }^{9}$ Contrast computed tomography (CT) is more valuable as it provides diagnostic precision. ${ }^{4}$ The American College of Radiology recommends the use of CT of the abdomen and pelvis with intra-venous (IV) contrast for patients with suspected acute small BO and either a CT abdomen and pelvis with IV contrast or a CT enterography for patients suspected to have intermittent or low-grade small BO. ${ }^{9}$

\section{Advanced care planning and goals of care conversations}

When patients with advanced cancers are diagnosed with MBO, clinicians should acknowledge that medical decisions are directed at extending life, minimizing distressing symptoms and maximizing quality of life. Care should be holistic and person-centred with focus on the interrelationship between physical, psychosocial, and spiritual issues. ${ }^{10}$ Clinicians should encourage patients to substitute decision makers who they can communicate their values and goals with to assist them with medical decision making when they no longer have capacity. In some jurisdictions, written advance care documents are legislated and may include options of appointing a formal decision-maker on loss of capacity, statements about values and goals and even binding refusals of specific interventions.

Before offering interventions for MBO management, clinicians should take into consideration the risks associated with the interventions in addition to the patient's estimated prognosis, performance status, comorbidities, location of care and ease of further assessment and support (e.g., home parenteral nutrition programs may not be universally available). Financial implications may also impact whether an intervention might be offered or undertaken. Further, patients may have strongly held views about the interventions that they would accept and their decisions can change over time, especially when the benefit of a therapy or an intervention may no longer exceed the burden and cessation may be considered appropriate by their clinicians or even desired by the patient. Clinicians are encouraged to discuss these possible scenarios with patients and their families before commencing interventions, such as total parenteral nutrition. As patients approach the end of their lives, their goals of care may shift from disease management and life prolongation to symptom management and quality of life. ${ }^{11}$

The interventions that might be offered or considered clinically appropriate may depend on the estimated prognosis of the patient. Physician prediction of survival is known to be inaccurate and often overly optimistic. Objective factors associated with short prognosis include deteriorating performance status and presence of other symptoms, potentially indicative of progressive malignant disease in other organs. ${ }^{12}$ Laboratory findings associated with systemic inflammatory response (e.g., elevated C-reactive protein), reduced albumin and leucocytosis are also associated with poor prognosis. ${ }^{13}$ Prognostic models 
incorporating physician prediction of survival and clinical and laboratory factors improve the accuracy of clinical prediction. ${ }^{14}$

The treating clinician should offer sensitive discussions with patients and their families about different treatment options that may be possible, what outcomes might be reasonably expected, possible adverse effects or burdens and how to measure whether such interventions may provide some success in terms of longevity, symptom control or improvement in quality of life. Assessments of a patient's illness understanding and decision-making, wishes around disclosure and acknowledging emotional responses are essential. ${ }^{15}$ Exploring these issues requires sensitivity and excellent communication skills. Generally, personal autonomy and the right to be involved in all medical decision-making is a widely held, but not a universal, principle. Some patients may choose not to confront their own mortality or lack capacity to do so. In certain cultures, patients may choose to defer medical decision-making to their family. Goals of care conversations require careful exploration, always with the patient's best interest being foremost.

\section{Methods}

\section{Literature review}

An information specialist (RF) conducted a systematic literature search in Medline ALL (Medline and Epub Ahead of Print and In-Process, In-Data-Review \& Other Non-Indexed Citations), Embase Classic +Embase, Cochrane Central Register of Controlled Trial, Cochrane Database of Systematic Reviews, Psyclnfo all from the OvidSP platform; Scopus from Elsevier, and Global Index Medicus (LILACS, WPRIM, IMEMR, IMSEAR, AIM) from WHO. The literature search was executed from the inception of each database to March 2021 with no language limitations. Each search strategy comprised a combination of controlled vocabulary terms and text words, adapting the database-specific search syntax. Where applicable, the search was restricted to human studies, adults $\geq 18$ years of age and excluded books, conference abstracts, and dissertations. Appendix A presents the Medline ALL search.

Records obtained were stored on EndNote citation software, following which duplicates were removed and studies uploaded onto Covidence. Abstracts were screened for eligibility and then full-text articles were assessed. Any discrepancies in study selection were resolved through consensus. Inclusion criteria were studies about people with advanced cancers (any type) with MBO (small and/or large bowel) that examined MBO interventions and reported on outcomes related to symptom management, BO resolution, prognosis, overall survival and/or quality of life. All types of primary research studies (with or without comparators) were included. Studies about anti-cancer treatments (e.g., chemotherapy, radiation) for MBO management and non-English studies were excluded. In total 17,565 studies were identified, and 3,450 duplicates removed. From 14,115 studies that were screened against title and abstract, 13,561 were excluded. A total of 554 studies were assessed for full-text eligibility and 397 studies were included for this review. Figure 1 presents the PRISMA flow diagram. Using the 2018 MASCC Guidelines Policy: Recommendations for MASCC Guideline Construction and the Endorsement of Externally Generated Guidelines, the level of evidence (Table 1) for each MBO intervention was determined and synthesized 
into suggestions or recommendations with gradings (Table 2). "Suggestions" are used for statements that are based on Level III, IV or Level V evidence. "Recommendations" are reserved for statements that are based on Level I or Level II evidence. Whereas, "no guideline possible" are used when there is insufficient evidence on which to base a guideline. This implies that there is little or no evidence regarding the practice in question, or that the panel lacks consensus on the interpretation of existing evidence.

\section{Suggestions/recommendations}

The following sections present each MBO management recommendation and their associated evidence. In complete MBO, medication should be administered intravenous or subcutaneously if available.

\section{Anti-emetics}

The 2021 MASCC guideline about select pharmacologic management of nausea and vomiting in MBO was released in August 2021 as an update to a previous guideline published in $2017 .{ }^{16}$ The following sections and Appendix B provide suggestions/recommendations for all anti-emetic drug classes reportedly used for MBO management and their associated existing evidence:-

\section{Anticholinergics}

Suggestion: The benefit of anticholinergics (hyoscine butylbromide) may be inferior to octreotide to reduce vomiting in $M B O$. (Level of evidence: III; Grade: $D$ ).

Hyoscine (scopolamine) butylbromide is an anticholinergic agent that reduces gastrointestinal secretions. A 2016 systematic review ${ }^{17}$ identified four randomized clinical trials with high Cochrane risk of bias that found somatostatin analogues (e.g., octreotide) were more effective than hyoscine butylbromide in reducing nausea and vomiting. ${ }^{18-21}$ Three case reports reported mixed findings, where two reported hyoscine butylbromide in combination with other drugs (e.g., octreotide, dexamethasone) was effective in reducing vomiting, ${ }^{22,23}$ and one that reported that it was ineffective for controlling vomiting ${ }^{24}$ Since the publication of that review, no new randomized clinical trials have been published. An alternative anticholinergic that can reportedly be used is glycopyrrolate. However, this review only identified one case report that reported that glycopyrrolate reduced nausea and vomiting in MBO. ${ }^{25}$ Appendix B presents the characteristics of all included studies about anticholinergic use in MBO.

\section{Butyrophenone antipsychotic}

Suggestion: Haloperidol, a butyrophenone antipsychotic, may be an effective anti-emetic in MBO, particularly for complete MBO. (Level of evidence: IV; Grade: B) 
Butyrophenone antipsychotics are commonly used as anti-psychotics for delirium management but are also used for management of nausea and vomiting in MBO. The main butyrophenone used is haloperidol. The review identified two cross-sectional studies ${ }^{26,27}$ and two case reports/series that reported on haloperidol's use in $\mathrm{MBO} .^{25,28}$ All studies suggested that haloperidol effectively relieve nausea and vomiting in $\mathrm{MBO}$ and is the preferred anti-emetic in complete $\mathrm{BO} .^{25-28}$

\section{Dopamine antagonist prokinetic}

Suggestion: Dopamine antagonist prokinetic drugs (e.g., metoclopramide, domperidone) may be effective for management of nausea, vomiting and restoring bowel transit time in partial MBO. Due to the potential increased risk of bowel perforation, it likely should be avoided in complete MBO. (Level of evidence: III; Grade B)

Dopamine antagonist prokinetic drugs block dopamine receptors. They enhanced increase lower esophageal sphincter pressure, gastric motility and, therefore, gastric emptying. ${ }^{29}$ The main prokinetic drugs used in MBO management are domperidone and metoclopramide. We identified two crosssectional studies ${ }^{26,27}$ and three case reports/series ${ }^{24,30,31}$ published between 1985 and 2016, that reported on their use in MBO. Of these studies, three studies found metoclopramide was effective for nausea, vomiting and restoring intestinal transit time $27,30,31$, particularly in incomplete BO ${ }^{27}$ However, two studies found that metoclopramide was ineffective for relieving these symptoms. ${ }^{24,26}$ Only one study reported on the use of domperidone and found it ineffective for control of vomiting. ${ }^{26}$

\section{Histamine $\left(\mathrm{H}_{1}\right)$ antagonist}

Suggestion: Histamine $\mathrm{H}_{1}$ antagonists, (e.g., dimenhydrinate, cyclizine) may be an effective anti-emetic in complete BO. (Level of evidence: IV; Grade D).

Histamine $\mathrm{H}_{1}$ antagonists are a drug class that are primarily used for management of motion sickness from vestibular stimulation. The main histamine $\mathrm{H}_{1}$ antagonist that is used is dimenhydrinate. This review identified only one cross-sectional study published in 1994 that reported histamine $\mathrm{H}_{1}$ antagonist use for nausea management in complete BO. ${ }^{27}$

\section{Phenothiazines}

Suggestion: Phenothiazines (e.g., chlorpromazine) may reduce nausea and vomiting in MBO. (Level of evidence: IV; Grade: D)

Phenothiazines are first-generation antipsychotic agents that can be used for the prevention and control of nausea and vomiting. Examples of phenothiazines are chlorpromazine, prochlorperazine and 
methotrimeprazine (also known as levomepromazine). The review identified one cross-sectional study that found chlorpromazine, methotrimeprazine and prochlorperazine effectively reduce nausea and vomiting in patients with MBO. ${ }^{26}$

\section{Serotonin (5-HT3) antagonists}

Suggestion: Granisetron, a serotonin ( $5 \mathrm{HT}_{3}$ antagonist) may reduce nausea and the frequency of vomiting in MBO. (Level of evidence: III; Grade D).

Serotonin $\left(5-\mathrm{HT}_{3}\right)$ antagonists act on receptors located in the chemoreceptor trigger zone to reduce nausea and vomiting. The review identified only one study published in 2009 that examined the use of a $5-\mathrm{HT}_{3}$ antagonist, granisetron, for $\mathrm{MBO}$ management. ${ }^{32}$ This study was a phase II clinical trial that found granisetron, in addition to dexamethasone and as needed haloperidol, significantly reduced the severity of nausea $(p<0.001)$ and number of episodes of vomiting $(p<0.001)$ before and after treatment. However, the reported incidence of constipation associated with granisetron ranges from $3 \%$ to $18 \% .{ }^{29}$ Further studies are required to assess its use in MBO.

\section{Somatostatin analogues}

Recommendation: Somatostatin analogues (octreotide, lanreotide) may reduce vomiting in MBO. (Levels of evidence: I; Grade A).

MBO can cause intestinal secretions to accumulate and contribute to bowel distention, result in nausea and vomiting. Octreotide is a somatostatin analogue that reduces intestinal and pancreas secretion and gastrointestinal motility, biliary contraction, and intestinal edema. ${ }^{20,33}$ Octreotide may be administered by subcutaneous bolus or continuous subcutaneous infusion. Its duration of activity is approximately 6 to 12 hours, with an average half-life elimination of 1.8 hours, thus necessitating a multiple daily dosing schedule. Given it has a short half-life, a long-acting depot formulation is available to be administered intramuscularly once a month. Further, another somatostatin analogue, lanretotide, is available as a longacting depot formulation. ${ }^{34,35}$

A 2016 systematic review of randomized control trials and quasi-randomized control trials, published between 1979 and 2016, identified seven studies that compared the effect of somatostatin analogues with placebo and/or other pharmacologic agents (e.g., hyoscine butylbromide) on vomiting. ${ }^{17}$ A metaanalysis was not possible given the heterogeneity in study design, outcomes and timing of end-points. ${ }^{17}$ Of these seven studies, five studies with high Cochrane risk of bias found the somatostatin analogues were more effective than hyoscine butylbromide ${ }^{18-21}$ and placebo $^{36}$ for reducing vomiting. Whereas, two studies with low Cochrane risk of bias found no significant difference in vomiting between somatostatin analogues and placebo in their primary end points. ${ }^{34,37} \mathrm{~A}$ secondary analysis of a randomized control 
trial originally published in 2015 examined the health-related quality of life in patients with inoperable $\mathrm{MBO}$ and found no difference in quality-of-life scores. ${ }^{38}$

\section{Thienobenzodiazepene (second generation) antipsychotic}

Suggestion: Thienobenzodiazepene antipsychotic (e.g., olanzapine) may reduce nausea and vomiting in MBO. (Level of evidence: IV; Grade: D).

Olanzapine is a second generation thienobenzodiazepine antipsychotic that antagonizes serotonin $5-\mathrm{HT}_{3}$ and $5-\mathrm{HT}_{2 \mathrm{c}}$ and dopamine $\mathrm{D}_{2}$ receptors, which may be responsible for its anti-emetic effects. We identified one cross-sectional study, published in 2012, that found olanzapine reduced the average nausea scores and frequency of vomiting in patients with advanced cancer and partial BO. ${ }^{39}$

\section{Laxatives}

Suggestion: Oral osmotic laxatives should be considered in the management of impaired bowel movements in partial bowel obstruction but should be avoided in complete MBO. (Level of evidence: $V$; Grade: D)

Patients with MBO present with reduced or no bowel movements. The review did not identify any studies that specifically examined the use of laxatives in this context. If patients have complete MBO, the use of laxatives is not recommended. Whereas, if patients have partial BO, the cautious use of oral osmotic laxatives (e.g., polyethylene glycol 3350, also known as macrogol) can be used. Osmotic laxatives draw water into the lumen of the bowel to soften stool and stimulate peristalsis. ${ }^{40}$ The use of bulk-forming laxatives (e.g., psyllium) is not advised as they will increase stool consistency and potentially worsen BO. ${ }^{40}$ If a digital rectal examination identifies a full rectum or fecal impaction, suppositories and fecal disimpaction can be considered in partial MBO. ${ }^{41}$ However, enemas should be used with caution and are generally not recommended in MBO due to the risk of bowel perforation. Stool softeners (e.g., docusate) may be used but their effect on bowel movement frequency is not well established.

\section{Analgesics}

Pain is experienced by 70 to $90 \%$ of patients with MBO. ${ }^{42}$ Causes include abdominal distention, bowel spasms and, in some cases, perforation. ${ }^{42}$ Pain can be intermittent, cramping or continuous in nature. ${ }^{4}$ The World Health Organization Guidelines for the Pharmacologic and Radiotherapeutic Management of Cancer pain in Adults and Adolescents recommend that analgesics should be given by mouth whenever possible. ${ }^{43}$ However, patients with MBO often have significant nausea and vomiting and malfunctioning gastrointestinal tracts that prevent ingestion and absorption of oral analgesics. Consequently, the parenteral (subcutaneous or intravenous) and/or transdermal routes of administration should be 
considered for this population to deliver effective analgesia. A comparison of subcutaneous and intravenous routes found no differences, confirming both routes as feasible, effective and safe. ${ }^{44}$

\section{Opioids}

Suggestion: Opioids are commonly used to treat pain associated with MBO but there is no evidence to support their use. (Level of evidence: V; Grade D)

Opioids are the mainstay analgesic for management of moderate and severe cancer-related pain, including in the context of MBO. The review did not identify any studies that specifically examined the use of opioids for pain management in MBO. Further study is warranted, especially given that opioids impair gastrointestinal motility and can cause nausea, vomiting and constipation. ${ }^{45}$

\section{Anticholinergics}

Suggestion: The benefit of anticholinergics (hyoscine butylbromide) may be effective to reduce abdominal pain in MBO. (Level of evidence: III; Grade: D).

Hyoscine (scopolamine) butylbromide is an anticholinergic agent that is widely used to treat spasmodic abdominal pain. In addition to reducing gastrointestinal secretions, it slows propulsive peristalsis, and relaxes smooth muscles of the gut. Hyoscine butylbromide is commonly recommended for the management of the inoperable MBO but scarce evidence supports its use. A 2016 systematic review ${ }^{17}$ identified two randomized clinical trials with high Cochrane risk of bias that found somatostatin analogues (e.g., octreotide) were more effective than hyoscine butylbromide in reducing continuous pain, ${ }^{20,21}$ but one trial did not find this finding. ${ }^{22}$ Whereas, all three trials did not find a significant difference in colicky pain between octreotide and hysoscine butylbromide. ${ }^{20-22}$ Two case reports reported hyoscine butylbromide in combination with other drugs (e.g., morphine, octreotide, dexamethasone) was effective in reducing abdominal pain. ${ }^{22,23}$

\section{Corticosteroids}

Suggestion: The use of steroids may help with the acute symptoms of $M B O$ and can be used for shortterm benefit (Level of evidence: III; Grade: B).

The role of corticosteroids in MBO is complex and the mechanism of action is not completely understood. Corticosteroids likely have an anti-inflammatory and anti-secretory effect, which may help decrease the intestinal wall edema, promote salt and water absorption in MBO and, therefore, help with acute management of pain, nausea and vomiting. ${ }^{46}$ Dexamethasone is generally the preferred corticosteroid given its potent anti-inflammatory effect, and lack of sodium-retaining properties. ${ }^{47}$ The optimal dose of corticosteroids for MBO management is not well established. A dose between 4 and 16 
mg of dexamethasone daily may be considered. ${ }^{34,48}$ In cases of no symptomatic improvement in 3 to 5 days, discontinuation should be considered. ${ }^{48}$

Unselected and uncontrolled case series have reported a benefit of corticosteroids for the management of BO; yet it is challenging to attribute whether the resolution of MBO related symptoms is due to the medication or potential spontaneous resolution. ${ }^{30,49,50}$ Moreover, some of these reports look at combination strategies of corticosteroids with other therapies, which makes it impossible to attribute the resolution of MBO to the corticosteroid therapy per se. ${ }^{34} \mathrm{~A}$ retrospective cohort study retrieved information from a Japanese national medical claims database that included 3,090 adult patients with MBO treated with octreotide. ${ }^{51}$ Octreotide alone, in combination with $\mathrm{H}_{2}$ antagonists, proton pump inhibitor or corticosteroids was administered in $53 \%, 14 \%, 11 \%$ and $12 \%$ of patients, respectively. A secondary endpoint of the study was the assessment of nasogastric tube removal at four days. Of the 1,595 patients who underwent a nasogastric tube insertion, those receiving corticosteroids with octreotide had a higher odds ratio (OR) of nasogastric tube removal within four days of insertion compared to those who did not receive octreotide (OR 1.16; 95\% confidence interval [Cl] 1.08 - 1.23).

A Cochrane systematic review and meta-analysis (updated search performed in 2017, with stable review) assessed the role of corticosteroids for MBO in patients with advanced gynecologic or

gastrointestinal tumours. ${ }^{48}$ Three double-blind placebo-controlled clinical trials involving 89 patients were included in the analysis. Two of the studies included in the meta-analysis were unpublished. In two of the trials patients with history of gastrointestinal haemorrhage, active peptic ulceration or signs of peritonitis were excluded, and intravenous dexamethasone at $16 \mathrm{mg}$ for five days was used. ${ }^{48,52}$ The third trial used methylprednisolone $40 \mathrm{mg}$ and $240 \mathrm{mg}$ intravenously for three days (dexamethasone equivalent $8 \mathrm{mg}$ and $48 \mathrm{mg}$; dosage was not considered in the analysis). ${ }^{48}$ The primary outcome of the study was the resolution of BO within 10 days of symptom onset. There was a trend that corticosteroids may be beneficial, with a point estimate of $0.51(95 \% \mathrm{Cl} 0.19-1.43)$. The number needed to treat with corticosteroids to resolve a BO was six. There was no effect of corticosteroids on mortality at one month. The study also concluded that the incidence of adverse events related to corticosteroids is very low; however, the use of lowest effective dose for the shortest period should be considered to avoid long-term adverse events. ${ }^{48}$ Concerns of long-term use include oral candidiasis, muscle proximal weakness, cushingoid habitus, gastric ulceration, infection risk, mood swings and sleep disturbances, among others.

In a multi-centre randomized trial assessing the role of octreotide in control of vomiting, dexamethasone (8 mg daily, intravenously), along with ranitidine and parenteral hydration was considered as the standardized supportive therapy for acute management of $\mathrm{MBO} .{ }^{34}$ There were no significant differences on the number of days free of vomiting between the octreotide and placebo groups. However, there was a significant drop in the mean number of vomiting episodes in both groups, suggesting that the standardized supportive therapy was helpful. The relative contribution of dexamethasone and/or ranitidine in reduction of vomiting could not be addressed given the study design. No other randomized 
controlled trials assessing the role of corticosteroids have been detected in our review following the updated search of the Cochrane systematic review.

\section{Oral water-soluble contrasts}

No guideline possible. There are insufficient data to determine the efficacy of oral water-soluble contrasts in $M B O$. (Level of evidence: $V$; Grade D)

Oral water-soluble contrasts are iodinated contrasts that are opaque on plain x-rays. ${ }^{53}$ The most common form used is gastrografin, a hyperosmolar solution that is a combination of sodium diatrizoate and meglumine diatrizoate. They can be used in the management of adhesive BO, as a tool to predict the resolution of adhesive small $\mathrm{BO}$ with conservative management, and it may also decrease the need for surgery and hospital stay. ${ }^{53} \mathrm{~A}$ Cochrane systematic review assessed the role of oral water-soluble contrast in $\mathrm{MBO}^{53}$ and identified only one randomized double-blinded placebo-controlled feasibility study with a high risk of bias, enrolled nine patients. ${ }^{54}$ The study assessed the role of gastrografin compared to placebo in patients with $\mathrm{MBO}$ and no indication for surgery or endoscopic interventions. The rate of resolution of $\mathrm{MBO}$ or ability to predict resolution of $\mathrm{MBO}$ was not reported. No safety signals were detected. A retrospective study assessed the role of gastrografin in the management of $\mathrm{BO} .{ }^{55}$ The administration of gastrografin challenge was considered safe. In the subgroup analysis of patients with active malignancy $(n=63)$, there were no differences in the need of surgical exploration or length in hospital stay between those who did and did not receive gastrografin. No other reports have been detected in our search following the publication of the Cochrane review.

\section{Bowel decompression}

Nasogastric tube and percutaneous gastrostomy insertion, either endoscopically or radiologically guided, are established techniques to provide enteral feeding. In the case of MBO, these measures are used as a venting/decompression procedure. The following sections provide suggestions/recommendations for all bowel decompression interventions and their associated existing evidence:

\section{Nasogastric tube}

Suggestion: Nasogastric tube may be used for temporary decompression in acute MBO (Level of evidence: $V$; Grade: D).

Temporary decompression via a wide bore nasogastric tube can evacuate a large amount of pooled gastric secretions, particularly during acute MBO episodes and improve symptoms. ${ }^{56}$ Based on clinical expertise and existing guidelines, it is not suggested for chronic MBO management because the nasogastric tubes are not well tolerated when placed for a prolonged time. ${ }^{57,58}$ Nasogastric tubes can 
become occluded or displaced, which may require flushing or replacement. Other potential complications include nasal cartilage erosion, otitis media, aspiration pneumonia, esophagitis, and bleeding. ${ }^{59}$

\section{Endoscopic or percutaneous gastrostomy tube}

Suggestion: Endoscopic or percutaneous gastrostomy tube may be used for gastric decompression in MBO (Level of evidence: IV; Grade B evidence).

A more permanent decompression of gastric contents can be achieved through placement of an endoscopic or percutaneous gastrostomy tube, also known as "venting gastrostomy". This review identified 29 studies that found gastrostomy insertion is generally feasible ${ }^{60-87}$ with high reduction in symptoms of nausea and vomiting. Major complications were rare, with most complications classified as minor wound infections or leakage of fluid around the tube. Presence of ascites is not an absolute contraindication to the insertion of percutaneous venting gastrostomy in patients with $\mathrm{MBO} ;{ }^{61,68,78}$ however, it is reasonable to suggest that ascitic drainage with paracentesis or placement of an intraperitoneal catheter is performed to reduce potential complications.

\section{Percutaneous transesophageal gastro-tubing}

Suggestion: Percutaneous transesophageal gastro-tubing may be used for gastric decompression in MBO (Level of evidence: IV; Grade: C).

This review identified four studies with a limited number of patients with MBO and are not candidates for surgical decompression or percutaneous/endoscopic gastrostomy tubes. ${ }^{88-91}$ The placement of percutaneous transesophageal gastro-tubing (PTEG) may be used to decompress gastric contents. A Japanese randomized controlled trial assessed PTEG or nasogastric (NG) tube in 40 patients with inoperable MBO. The PTEG resulted in fewer symptoms and higher quality of life compared with nasogastric tubes. ${ }^{88}$ The primary endpoint was symptom palliation for two weeks (non-validated questionnaire), and showed lower symptom burden in those patients with PTEG. Secondary endpoints included quality of life measures (EQ-5D and SF-8 scores), which were significantly higher in the PTEG group. No differences in overall survival were detected between the two groups.

\section{Palliative Surgery and Stents}

Recommendation and suggestions

- Self-expanding metallic stents are the preferred alternative for the management of a single-level large bowel obstruction, when technically feasible, and in the absence of colonic perforation. (Level of evidence: II; Grade: B). Surgical palliation may be considered as an alternative in selected cases. 
- In the case of a multi-level obstruction, palliative surgical intervention may be considered in a highly selected population. (Level of evidence: IV; Grade: B).

- Patients with advanced cancer that undergo palliative surgery for MBO are at high risk of surgical complications, and less invasive surgical interventions should be considered. (Level of evidence: IV; Grade: B).

Interventions in single-level obstruction may include decompression methods or open surgery with bypass or stoma. ${ }^{92}$ Obtaining a surgical opinion should be considered at the time of MBO diagnosis. Stoma formation is preferred if the length of the proximal intestine ensures gastrointestinal autonomy (low risk of short bowel syndrome) or if the risk of complications related to intra-abdominal anastomosis is too high. ${ }^{93}$ The large bowel decompression options may include colonic decompression tubes, ablative methods, and the use of self-expanding metal stents (SEMS). ${ }^{94}$ The SEMS are generally the preferred decompression method as they have shown higher success rates than decompression tubes. ${ }^{95,96}$ Decompression methods are not indicated in patients with a perforation. ${ }^{94}$

Most studies assessing the role of SEMS in MBO have included mixed populations (curative intent with the stent placement as a bridge-to-surgery and palliative). ${ }^{97-102}$ The role of the stent as bridge-to-surgery is out of the scope of this guideline. In a meta-analysis of patients with large BO caused by colorectal cancer undergoing SEMS placement or emergency surgery with a palliative intent, eighteen studies (randomized controlled trials and comparative observational studies) with 1,518 patients were selected. Results showed that 30-day mortality was higher in those patients undergoing a surgical procedure (OR $0.4 ; 95 \% \mathrm{Cl} 0.28-0.69) .{ }^{103}$ Early complications were more frequent in the surgical group, whereas late complications occurred more frequently after SEMS, mainly re-obstructions. Another meta-analysis in the same setting only including randomized controlled trials (four studies, 125 patients), showed no differences in 30-day mortality or mean survival between those patients undergoing SEMS or emergency surgery, with a shorter hospital stay in SEMS group. ${ }^{104}$ Another randomized controlled trial assessed the role of stent insertion or surgical decompression for non-curable large BO. ${ }^{105}$ Results showed that the combined costs were lower in those patients treated with stent. In terms of quality of life, measured by European Quality of Life Five Dimension (EQ-5D) scores, no differences were detected at four-weeks between the two groups.

Most of the studies assessing the role of palliative surgery for multi-focal or small bowel MBO are retrospective in nature. A Cochrane systematic review of studies that assessed the role of surgery for MBO in advanced gynaecologic or colorectal cancer identified 43 studies with a total of 4,265 participants. ${ }^{2}$ Most studies were retrospective, of low methodological quality and high risk of bias. Additionally, some studies included mixed populations with benign and malignant cause of BO. Reobstruction rates post-surgical laparotomy, when reported, ranged from $10 \%$ to $63 \%$, with limited time to re-obstruction data. The ability to feed orally ranged between $30-100 \%$. When reported, postoperative mortality within 30 days was $0 \%$ to $32 \%$ and postoperative morbidity ranged from $22 \%$ to $87 \%$. It was not possible to conclude whether there was benefit of using surgery in this setting. Following the publication 
of the Cochrane review, no randomized trials have been detected in our review. However, other systematic reviews have focused on studies assessing the role of surgery in specific populations with MBO, including patients with small BO or peritoneal carcinomatosis. ${ }^{93,106}$ Similarly, it was not possible to conclude if there is benefit on surgery in this setting, as most studies were retrospective, of low methodological quality, and high selection bias in those deemed appropriate for surgical intervention. It may be reasonable to select patients that are more likely to benefit from the procedure, including good performance status, and to focus the surgical intervention on relieving symptoms.

\section{Nutrition}

Oral intake is significantly impaired in MBO and raises important questions about hydration and nutrition, which should be carefully considered and discussed with the patient and their substitute decision makers.

\section{Diet}

\section{Suggestions:}

- When a patient is initially diagnosed with MBO, they should be made Nil Per Os (NPO; nothing by mouth) and then when the acute MBO resolves fully or partially, a symptom led, slow and graded reintroduction to oral diet is recommended. This may include clear fluids, free or full fluids, texture modified low fibre diet (soft, minced, pureed) and back to normal textured low fibre diet. (Level of evidence: IV; Grade: B).

- Nutrition interventions should be initiated in patients with advanced cancers only where the benefits of these intervention on quality of life and survival outweigh the risks with clear expectations discussed by a multidisciplinary team with patients and families. (Level of evidence: IV; Grade: B).

Patients admitted with acute onset of a MBO are made nil by mouth with the addition of a decompressive nasogastric tube and/or venting gastrostomy to control symptoms such as nausea and vomiting. 2,107,108 Managing the nutrition requirements of patients presenting with advanced cancers and MBO is controversial and ethically challenging as there is no consensus due to scant published evidence. $5,109,110$ Nutrition interventions must be considered in the context of the patient's prognosis with the focus on prioritising the patient's wishes. ${ }^{111}$ Awareness of the sociocultural meaning of food and nutrition for many people is an important consideration and may contribute to increases in quality of life. ${ }^{111,112}$

As a patient's acute MBO resolves, either fully or partially, a symptom led, slow and graded reintroduction to oral diet is recommended. This may include clear fluids, free or full fluids, texture modified low fibre diet (soft, minced, pureed) and back to normal textured low fibre diet. A low fibre diet is one that contains a maximum of $10 \mathrm{~g}$ of fibre per day. A low fibre diet is thought to be beneficial due to a reduction in stool bulk which may lead to reduced pain, abdominal cramps, gas or feeling of fullness, particularly in those 
people with ongoing subacute $\mathrm{BO} .{ }^{110}$ General recommendations also include a grazing eating pattern, with small volumes of food and fluid consumed at any one time. Nutrition education to assist the patient and family to modify their diet according to symptoms is required to enhance autonomy and selfmanagement.

\section{Hydration}

\section{Suggestions}

- Parenteral hydration does not prevent or improve symptoms, such as thirst or dry mouth, nor it increases survival, and in excessive amounts, it may bring on fluid overload, peripheral and pulmonary edema. (Level of evidence: III; Grade: B).

- Parenteral hydration should not be initiated routinely in the last days of life (Level of evidence: III; Grade: $B$ )

Hydration is an element of parenteral nutrition, ${ }^{42}$ yet hydration may be delivered without nutrition, and it should be considered separately as a means of palliative care to relieve symptoms, not prolonging life. ${ }^{113}$ Parenteral hydration $(\mathrm{PH})$ means providing fluids infusion by the route other than oral or enteral (i.e., intravenously or subcutaneously; hypodermoclysis). ${ }^{111}$ Hypodermoclysis is an effective, and safe route of hydrating a patient up to $1,500 \mathrm{~mL} /$ day, with few local adverse effects; ${ }^{114}$ with attention to water and electrolytes balance. $\mathrm{PH}$ is an element of palliative care and should follow predefined realistic treatment goals.

In a small prospective randomized trial of patients with inoperable $\mathrm{MBO}$, the amount of parenterally supplied fluids was not associated with thirst, dry mouth intensity, or abdominal distension, but in a volume of $>500 \mathrm{~mL} /$ day might reduce nausea and drowsiness. ${ }^{20}$ However, a high level of $\mathrm{PH}$ may result in more gastrointestinal secretions. ${ }^{3}$

A Cochrane review found an insufficient number of low risk of bias studies, which does not allow formulation of any clinical practice recommendations about medically assisted $\mathrm{PH}$ in palliative care patients. ${ }^{115}$ All the studies included in the Cochrane review only had participants with advanced cancer, but it was not reported whether they had MBO. Our review did not detect specific studies assessing PH at the end-of-life, specifically in patients with MBO. At the end of life, $\mathrm{PH}$ may not be beneficial. ${ }^{116}$ In a systematic review of practices in the last week of life of patients with cancer, PH did not improve symptoms such as thirst and delirium, although data to support or discourage it is scarce. ${ }^{117}$ Dehydration is a frequent cause of delirium, and $\mathrm{PH}$ may appear effective, except in the dying phase when even moderate amounts of artificial hydration may be harmful. $\mathrm{PH}$ in the dying phase may increase the risk of fluid overload, peripheral swelling, ascites, and pulmonary edema. ${ }^{116}$ In a multi-centre, double-blind placebo-controlled randomized study, subcutaneous infusion of $1,000 \mathrm{~mL}$ daily did not improve 
symptoms of dehydration (fatigue, myoclonus, sedation, hallucinations), quality of life, or survival at the end of life. ${ }^{118}$

\section{Parenteral nutrition}

\section{Suggestions:}

- HPN may be beneficial and maintain the quality of life in a very selected group of patients with MBO (Level of evidence: IV; Grade: D).

- Central venous access is preferred for HPN delivery (Level III, Grade: B).

- In end-of-life HPN should be discontinued (or not initiated) as it raises the risk of complications and may prolong suffering (Level of evidence: $V$; Grade: $D$ ).

The following terms are used to describe parenteral nutrition: "total parenteral nutrition" (TPN): nutrition administered exclusively intravenously; "supplemental parenteral nutrition (SPN)": nutrition administered intravenously and enterally, regardless of proportion, orally or by artificial access; and "home parenteral nutrition" (HPN): parenteral nutrition (regardless TPN or SPN) administered at home.

Feeding through the peripheral veins may cause phlebitis and the need for reintroduction of vein access. It may cause patient suffering and require additional medical procedures. Feeding through the central veins (e.g., Broviac catheter, vascular access port, peripherally inserted central catheter) is advised, as it ensures long-term safe access upon the strict aseptic protocol is followed. ${ }^{119,120}$

Most studies assessing the role of parenteral nutrition are retrospective. A Cochrane systematic review assessed the effectiveness of HPN in survival and quality of life in patients with inoperable MBO. ${ }^{121}$ Thirteen studies (all observational with high risk of bias), including 721 participants were included. The median survival intervals were variable, between 15 to 155 days. ${ }^{121}$ Only three studies reported validated quality of life measures, showing equivocal results (one study reported improvements during the first three months and two studies showed an equal number of patients with improved and deteriorated quality of life)..$^{122-124}$

HPN can be associated with risk of complications (metabolic and/or catheter-related). In the Cochrane systematic review adverse events were measured by nine studies, showing that between $6 \%$ and $21 \%$ of patients developed a central venous catheter infection or were hospitalized because of complications related to parenteral nutrition. ${ }^{121}$ The use of HPN also involves financial, personnel, and infrastructure resources. A meta-analysis included a health economic evaluation of HPN in this setting. ${ }^{125}$

There is a need to weigh the benefits and risks when recommending HPN, including the predicted cancerrelated survival. ${ }^{125-127}$ Potential prognostic criteria for survival and benefit of HPN may include: i) histopathological type of the tumor-slow-growing and chemo-sensitive cancer, ${ }^{128-131} i$ i) performance 
status-ECOG <2, iii) no fluid retention (peripheral edema, pleural or peritoneal effusion), iv) no anemia, and $v$ ) no hypoalbuminemia. ${ }^{132}$ This evaluation should be reassessed over-time.

Most patients may not benefit from HPN due to clinical deterioration resulted from cancer progression, chronic cancer treatment, ${ }^{133}$ latent infection, ${ }^{134}$ depression (up to $24 \%$ ), ${ }^{135,136}$ and suboptimal nutritional treatment. ${ }^{137}$ Malnutrition and cachexia in patients with advanced cancer and MBO are usually irreversible and treatment-resistant. ${ }^{138}$ Therefore, the goal of the treatment is to maintain the nutritional status and achieve functional (through physiotherapy and nutrition), symptomatic, associative and mental function improvement.

The European Society for Clinical Nutrition and Metabolism (ESPEN) practical guideline for clinical nutrition in patients with cancer suggests that in dying patients, treatment recommendations should be based on comfort. Parenteral hydration and nutrition are unlikely to provide any benefit for most patients at the end of life. ${ }^{109}$

\section{Psychosocial Support}

The course of $\mathrm{MBO}$ can be unpredictable with a range of complex and challenging symptoms, which can be difficult to manage for both the patient and their family. The importance of family and supportive care is firmly established within palliative and end-of-life care literature. ${ }^{139,140}$ Although the need for emotional and psychological support for both patient and family in the context of MBO is equally acknowledged, high quality studies which focus specifically on the context of MBO are limited. ${ }^{141,142}$ Evidence has been based on clinical case reviews, small scale qualitative descriptive studies or current best practice opinion.

Unmet psychosocial need has been identified as a significant issue in patients with ovarian cancer and MBO, as it is often poorly addressed. The need for a multidisciplinary approach to care is promoted. ${ }^{143} \mathrm{~A}$ qualitative study described the benefits of a model of supported self-management for women with advanced gynaecological cancers attending out-patient clinics. Clear communication, counselling and referral to early palliative care were identified as important considerations. ${ }^{144} \mathrm{~A}$ separate qualitative study with oncologists treating gynaecological cancers identified that early palliative care referral was beneficial, particularly in situations where patients were not candidates for surgery. ${ }^{145}$ However, patients' expectations of their oncologists were not always met, suggesting strengthening of communication strategies and protocols is needed.

Given the nature and range of complex symptoms associated with MBO, early palliative care has been suggested. Optimal treatment requires a realistic assessment of goals of care with important communication about prognosis, management of symptoms and end-of-life care. A recent review of the surgical management of MBO suggests careful decision-making with patient and family to ensure the most appropriate outcome. ${ }^{146}$ A 2018 systematic review focused on the burden of care placed on family 
caregivers as a result of home-based parenteral nutrition for women with advanced ovarian cancer and MBO found that caregivers described an experience of vulnerability and family disruption caused by the decision to care for the patient at home. Conversely, in acknowledging the challenges placed on the family, patients recognized the lifeline given to them in terms of spending quality time with their family by this option for home care. ${ }^{121}$

\section{Conclusion}

MBO is a significant complication for patients living with cancer. The approach should be multi and interdisciplinary to improve the management of these patients and support their family. Studies indicate the need to improve the quality of research and subsequent interventions in this domain. Communication around changing goals of care is essential to foster clear and decisive clinical decision making in partnership with patients and families. Further prospective and innovative studies are needed to improve the care for patients with MBO.

\section{Declarations}

\section{Ethics approval}

Ethics approval was not required for this study.

\section{Consent}

This study did not directly involve any human subjects and, therefore, consent was not applicable for this study.

\section{Data, material and code availability.}

The review search strategy and data are available upon reasonable request.

\section{Authors contribution statement}

All authors were involved in the conception and design, data analysis and interpretation, and manuscript drafting. $\mathrm{AH}, \mathrm{JL}$ and $\mathrm{SL}$ were involved in data acquisition and final editing.

\section{Funding}

The authors received in-kind support from the Multinational Association of Supportive Care in Cancer.

No funding was received to assist with the presentation of this manuscript. 
No funding was received for conducting this study.

No funds, grants, or other support was received.

\section{Conflicts of Interests/Completing Interests}

The authors have no conflicts of interest to declare that are relevant to the content of this article.

All authors certify that they have no affiliations with or involvement in any organization or entity with any financial interest or non-financial interest in the subject matter or materials discussed in this manuscript.

The authors have no financial or proprietary interests in an material discussed in this article.

\section{Acknowledgements:}

The authors would like to thank MASCC for their in-kind support. The authors would also like to acknowledge Caleb Nault for his help in the article retrieval.

\section{References}

1. Anthony T, Baron T, Mercadante S et al (2007) : Report of the clinical protocol committee: development of randomized trials for malignant bowel obstruction.J Pain Symptom Manage34:S4959

2. Cousins SE, Tempest E, Feuer DJ (2016) : Surgery for the resolution of symptoms in malignant bowel obstruction in advanced gynaecological and gastrointestinal cancer.Cochrane Database Syst Rev:CD002764,

3. Ripamonti Cl, Easson AM, Gerdes H (2008) : Management of malignant bowel obstruction.Eur J Cancer44:1105-15

4. Lee YC, Jivraj N, O'Brien C et al (2018) : Malignant Bowel Obstruction in Advanced Gynecologic Cancers: An Updated Review from a Multidisciplinary Perspective.Obstet Gynecol Int2018:1867238

5. Outcomes following small (2019) bowel obstruction due to malignancy in the national audit of small bowel obstruction.Eur J Surg Oncol45:2319-2324

6. Patel PS, Fragkos KC, Keane N et al (2021) : Clinical and Nutritional Care Pathways of Patients with Malignant Bowel Obstruction: A Retrospective Analysis in a Tertiary UK Center.Nutr Cancer73:572587

7. Yim GW, Eoh KJ, Kim SW et al (2016) : Malnutrition Identified by the Nutritional Risk Index and Poor Prognosis in Advanced Epithelial Ovarian Carcinoma.Nutr Cancer68:772-9

8. Marshall KM, Loeliger J, Nolte L et al (2019) : Prevalence of malnutrition and impact on clinical outcomes in cancer services: A comparison of two time points.Clin Nutr38:644-651 
9. Chang KJ, Marin D, Kim DH et al (2020) : ACR Appropriateness Criteria ${ }^{\circledR}$ Suspected Small-Bowel Obstruction.J Am Coll Radiol17:S305-s314

10. Puchalski CM, Sbrana A, Ferrell B et al (2019) : Interprofessional spiritual care in oncology: a literature review.ESMO Open4:e000465

11. Crawford GB, Dzierżanowski T, Hauser $\mathrm{K}$ et al (2021) : Care of the adult cancer patient at the end of life: ESMO Clinical Practice Guidelines.ESMO Open6:100225

12. Hui D, Hess K, dos Santos R et al (2015) : A diagnostic model for impending death in cancer patients: Preliminary report.Cancer121:3914-21

13. Dolan RD, McSorley ST, Horgan PG et al (2017) : The role of the systemic inflammatory response in predicting outcomes in patients with advanced inoperable cancer: Systematic review and metaanalysis.Crit Rev Oncol Hematol116:134-146

14. Simmons CPL, McMillan DC, McWilliams K et al Prognostic Tools in Patients With Advanced Cancer: A Systematic Review.J Pain Symptom Manage53:962-970.e10, 2017

15. Gilligan T, Coyle N, Frankel RM et al (2017) : Patient-Clinician Communication: American Society of Clinical Oncology Consensus Guideline.J Clin Oncol35:3618-3632

16. Davis M, Hui D, Davies A et al (2021) : Medical management of malignant bowel obstruction in patients with advanced cancer: 2021 MASCC guideline update.Support Care Cancer,

17. Obita GP, Boland EG, Currow DC et al Somatostatin Analogues Compared With Placebo and Other Pharmacologic Agents in the Management of Symptoms of Inoperable Malignant Bowel Obstruction: A Systematic Review.J Pain Symptom Manage52:901-919.e1, 2016

18. Mercadante S, Ripamonti C, Casuccio A et al (2000) : Comparison of octreotide and hyoscine butylbromide in controlling gastrointestinal symptoms due to malignant inoperable bowel obstruction.Support Care Cancer8:188-91

19. Peng X, Wang P, Li S et al (2015) : Randomized clinical trial comparing octreotide and scopolamine butylbromide in symptom control of patients with inoperable bowel obstruction due to advanced ovarian cancer.World Journal of Surgical Oncology13,

20. Ripamonti C, Mercadante S, Groff L et al (2000) : Role of octreotide, scopolamine butylbromide, and hydration in symptom control of patients with inoperable bowel obstruction and nasogastric tubes: a prospective randomized trial.J Pain Symptom Manage19:23-34

21. Mystakidou K, Tsilika E, Kalaidopoulou $O$ et al (2002) : Comparison of octreotide administration vs conservative treatment in the management of inoperable bowel obstruction in patients with far advanced cancer: a randomized, double- blind, controlled clinical trial.Anticancer Res22:1187-92

22. De Conno F, Caraceni A, Zecca E et al (1991) : Continuous subcutaneous infusion of hyoscine butylbromide reduces secretions in patients with gastrointestinal obstruction.J Pain Symptom Manage6:484-6

23. Weber C, Zulian GB (2009) : Malignant irreversible intestinal obstruction: the powerful association of octreotide to corticosteroids, antiemetics, and analgesics.Am J Hosp Palliat Care26:84-8 
24. Mercadante S (1998) : Scopolamine butylbromide plus octreotide in unresponsive bowel obstruction.J Pain Symptom Manage16:278-80

25. Davis MP, Furste A (1999) : Glycopyrrolate: a useful drug in the palliation of mechanical bowel obstruction.J Pain Symptom Manage18:153-4

26. Baines M, Oliver DJ, Carter RL (1985) : Medical management of intestinal obstruction in patients with advanced malignant disease. A clinical and pathological study.Lancet2:990-3

27. Fainsinger RL, Spachynski K, Hanson J et al (1994) : Symptom control in terminally ill patients with malignant bowel obstruction (MBO).J Pain Symptom Manage9:12-8

28. Muir JC, von Gunten CF (2001) : Abdominal cancer, nausea, and vomiting.J Palliat Med4:391-4

29. Lexi-drugs online [database on the Internet]. Hudson (OH): Lexicomp, Inc.; 2021 [updated 23 Sept 2021; cited 26 Sept 2021]. Available from: http://online.lexi.com. Subscription required to view

30. Berger J, Lester P, Rodrigues L (2016) : Medical Therapy of Malignant Bowel Obstruction With Octreotide, Dexamethasone, and Metoclopramide.Am J Hosp Palliat Care33:407-10

31. Mercadante S, Ferrera P, Villari P et al (2004) : Aggressive pharmacological treatment for reversing malignant bowel obstruction.J Pain Symptom Manage28:412-6

32. Tuca A, Roca R, Sala C et al (2009) : Efficacy of granisetron in the antiemetic control of nonsurgical intestinal obstruction in advanced cancer: a phase II clinical trial.J Pain Symptom Manage37:25970

33. Clare C, Bennett M (2002) : Tolerance issues in the use of somatostatin analogs in palliative care [1].Journal of Pain and Symptom Management23:87-88

34. Currow DC, Quinn S, Agar M et al (2015) : Double-blind, placebo-controlled, randomized trial of octreotide in malignant bowel obstruction.J Pain Symptom Manage49:814-21

35. Matulonis UA, Seiden MV, Roche M et al (2005) : Long-acting octreotide for the treatment and symptomatic relief of bowel obstruction in advanced ovarian cancer.J Pain Symptom Manage30:563-9

36. Laval G, Rousselot H, Toussaint-Martel S et al (2012) : SALTO: a randomized, multicenter study assessing octreotide LAR in inoperable bowel obstruction.Bulletin du Cancer99:E1-E9

37. Mariani P, Blumberg J, Landau A et al (2012) : Symptomatic treatment with lanreotide microparticles in inoperable bowel obstruction resulting from peritoneal carcinomatosis: a randomized, doubleblind, placebo-controlled phase III study.Journal of clinical oncology30:4337-4343

38. McCaffrey N, Asser T, Fazekas B et al (2020) : Health-related quality of life in patients with inoperable malignant bowel obstruction: secondary outcome from a double-blind, parallel, placebo-controlled randomised trial of octreotide.BMC Cancer20:1050

39. Kaneishi K, Kawabata M, Morita T (2012) : Olanzapine for the relief of nausea in patients with advanced cancer and incomplete bowel obstruction.J Pain Symptom Manage44:604-7

40. Bashir A, Sizar O Laxatives. [Updated 2021 Sep 4]. In: StatPearls [Internet]. Treasure Island (FL): StatPearls Publishing; 2021 Jan. Available from: https://www.ncbi.nlm.nih.gov/books/NBK537246/ 
Accessed on: 20th July, 2021

41. Larkin PJ, Cherny NI, La Carpia D et al (2018) : Diagnosis, assessment and management of constipation in advanced cancer: ESMO Clinical Practice Guidelines.Ann Oncol29:iv111-iv125

42. Tuca A, Guell E, Martinez-Losada E et al (2012) : Malignant bowel obstruction in advanced cancer patients: epidemiology, management, and factors influencing spontaneous resolution.Cancer Manag Res4:159-69

43. WHO Guidelines for the pharmacological (June 2021) and radiotherapeutic management of cancer pain in adults and adolescents. 1January 2019. https://www.who.int/publications/i/item/9789241550390 Accessed on: 1st

44. Radbruch L, Trottenberg P, Elsner F et al (2011) : Systematic review of the role of alternative application routes for opioid treatment for moderate to severe cancer pain: an EPCRC opioid guidelines project.Palliat Med25:578-96

45. Kraichely RE, Arora AS, Murray JA (2010) : Opiate-induced oesophageal dysmotility.Aliment Pharmacol Ther31:601-6

46. Hsu K, Prommer E, Murphy MC et al (2019) : Pharmacologic Management of Malignant Bowel Obstruction: When Surgery Is Not an Option.J Hosp Med14:367-373

47. TABLETS DECADRON® (DEXAMETHASONE TABLETS, USP). U.S. Food and Drug Administration website.

https://www.accessdata.fda.gov/drugsatfda_docs/label/2004/11664slr062_decadron_lbl.pdf Accessed on 15th August 2021

48. Feuer DJ, Broadley KE (2000) : Corticosteroids for the resolution of malignant bowel obstruction in advanced gynaecological and gastrointestinal cancer.Cochrane Database Syst Rev:Cd001219, 2000

49. Laval G, Arvieux C, Stefani L et al (2006) : Protocol for the treatment of malignant inoperable bowel obstruction: a prospective study of 80 cases at Grenoble University Hospital Center.J Pain Symptom Manage31:502-12

50. Philip J, Lickiss N, Grant PT et al (1999) : Corticosteroids in the management of bowel obstruction on a gynecological oncology unit.Gynecol Oncol74:68-73

51. Minoura T, Takeuchi M, Morita T et al Practice Patterns of Medications for Patients With Malignant Bowel Obstruction Using a Nationwide Claims Database and the Association Between Treatment Outcomes and Concomitant Use of $\mathrm{H}_{2}$-Blockers/Proton Pump Inhibitors and Corticosteroids With.J Pain Symptom Manage55:413-419.e2, 2018

52. Hardy J, Ling J, Mansi J et al (1998) : Pitfalls in placebo-controlled trials in palliative care: dexamethasone for the palliation of malignant bowel obstruction.Palliat Med12:437-42

53. Syrmis W, Richard R, Jenkins-Marsh S et al (2020) : Oral water soluble contrast for malignant bowel obstruction.Cochrane Database of Systematic Reviews,

54. Lee C, Vather R, O'Callaghan A et al (2013) : Validation of the phase II feasibility study in a palliative care setting: gastrografin in malignant bowel obstruction.Am J Hosp Palliat Care30:752-8 
55. Khasawneh MA, Eiken PW, Srvantstyan B et al Use of the Gastrografin challenge in patients with a history of abdominal or pelvic malignancy.Surgery154:769-75; discussion 775, 2013

56. Dolan EA (2011) : Malignant bowel obstruction: a review of current treatment strategies.Am J Hosp Palliat Care28:576-82

57. Laval G, Marcelin-Benazech B, Guirimand F et al (2014) : Recommendations for bowel obstruction with peritoneal carcinomatosis.Journal of Pain and Symptom Management48:75-91

58. Ripamonti C, Twycross R, Baines M et al (2001) : Clinical-practice recommendations for the management of bowel obstruction in patients with end-stage cancer.Support Care Cancer9:223-33

59. Prabhakaran S, Doraiswamy VA, Nagaraja V et al (2012) : Nasoenteric tube complications.Scand J Surg101:147-55

60. Malone JM Jr, Koonce T, Larson DM et al (1986) : Palliation of small bowel obstruction by percutaneous gastrostomy in patients with progressive ovarian carcinoma.Obstet Gynecol68:431-3

61. Lee MJ, Saini S, Brink JA et al (1991) : Malignant small bowel obstruction and ascites: not a contraindication to percutaneous gastrostomy.Clin Radiol44:332-4

62. Herman LL, Hoskins WJ, Shike M (1992) : Percutaneous endoscopic gastrostomy for decompression of the stomach and small bowel.Gastrointest Endosc38:314-8

63. Adelson MD, Kasowitz MH (1993) : Percutaneous endoscopic drainage gastrostomy in the treatment of gastrointestinal obstruction from intraperitoneal malignancy.Obstet Gynecol81:467-71

64. Marks WH, Perkal MF, Schwartz PE (1993) : Percutaneous endoscopic gastrostomy for gastric decompression in metastatic gynecologic malignancies.Surg Gynecol Obstet177:573-6

65. Cannizzaro R, Bortoluzzi F, Valentini M et al (1995) : Percutaneous endoscopic gastrostomy as a decompressive technique in bowel obstruction due to abdominal carcinomatosis.Endoscopy27:31720

66. Cunningham MJ, Bromberg C, Kredentser DC et al (1995): Percutaneous gastrostomy for decompression in patients with advanced gynecologic malignancies.Gynecol Oncol59:273-6

67. Campagnutta E, Cannizzaro R, Gallo A et al (1996) : Palliative treatment of upper intestinal obstruction by gynecological malignancy: The usefulness of percutaneous endoscopic gastrostomy.Gynecologic Oncology62:103-105

68. Ryan JM, Hahn PF, Mueller PR (1998) : Performing radiologic gastrostomy or gastrojejunostomy in patients with malignant ascites.AJR Am J Roentgenol171:1003-6

69. Scheidbach H, Horbach T, Groitl $\mathrm{H}$ et al (1999) : Percutaneous endoscopic gastrostomy/jejunostomy (PEG/PEJ) for decompression in the upper gastrointestinal tract. Initial experience with palliative treatment of gastrointestinal obstruction in terminally ill patients with advanced carcinomas.Surg Endosc13:1103-5

70. Brooksbank MA, Game PA, Ashby MA (2002) : Palliative venting gastrostomy in malignant intestinal obstruction.Palliat Med16:520-6 
71. Jolicoeur L, Faught W (2003) : Managing bowel obstruction in ovarian cancer using a percutaneous endoscopic gastrostomy (PEG) tube.Can Oncol Nurs J13:212-9

72. Piccinni G, Angrisano A, Testini M et al (2005) : Venting direct percutaneous jejunostomy (DPEJ) for drainage of malignant bowel obstruction in patients operated on for gastric cancer.Support Care Cancer13:535-9

73. Pothuri B, Montemarano M, Gerardi M et al (2005) : Percutaneous endoscopic gastrostomy tube placement in patients with malignant bowel obstruction due to ovarian carcinoma.Gynecol Oncol96:330-4

74. Chakraborty A, Selby D, Gardiner K et al (2011) : Malignant bowel obstruction: natural history of a heterogeneous patient population followed prospectively over two years.J Pain Symptom Manage41:412-20

75. Vashi PG, Dahlk S, Vashi RP et al (2011) : Percutaneous endoscopic gastrostomy tube occlusion in malignant peritoneal carcinomatosis-induced bowel obstruction.Eur J Gastroenterol Hepatol23:1069-73

76. Rath KS, Loseth D, Muscarella P et al (2013) : Outcomes following percutaneous upper gastrointestinal decompressive tube placement for malignant bowel obstruction in ovarian cancer.Gynecol Oncol129:103-6

77. Anouar T, Jamie G, Nilesh C (2012) : Percutaneous endoscopic gastrostomy tube placement for endstage palliation of malignant gastrointestinal obstructions, pp95-98

78. Shaw C, Bassett RL, Fox PS et al (2013) : Palliative venting gastrostomy in patients with malignant bowel obstruction and ascites.Ann Surg Oncol20:497-505

79. Issaka RB, Shapiro DM, Parikh ND et al (2014) : Palliative venting percutaneous endoscopic gastrostomy tube is safe and effective in patients with malignant obstruction.Surg Endosc28:166873

80. Kawata N, Kakushima N, Tanaka M et al (2014) : Percutaneous endoscopic gastrostomy for decompression of malignant bowel obstruction.Dig26:208-13

81. DeEulis TG, Yennurajalingam S (2015) : Venting Gastrostomy at Home for Symptomatic Management of Bowel Obstruction in Advanced/Recurrent Ovarian Malignancy: A Case Series.J Palliat Med18:722-8

82. Zucchi E, Fornasarig M, Martella L et al (2016) : Decompressive percutaneous endoscopic gastrostomy in advanced cancer patients with small-bowel obstruction is feasible and effective: a large prospective study.Support Care Cancer24:2877-82

83. Dittrich A, Schubert B, Kramer M et al (2017) : Benefits and risks of a percutaneous endoscopic gastrostomy (PEG) for decompression in patients with malignant gastrointestinal obstruction.Support Care Cancer25:2849-2856

84. Singh Curry R, Evans E, Raftery AM et al (2019): Percutaneous venting gastrostomy/gastrojejunostomy for malignant bowel obstruction: a qualitative study.BMJ support9:381-388 
85. Pinard KA, Goring TN, Egan BC et al (2017) : Drainage Percutaneous Endoscopic Gastrostomy for Malignant Bowel Obstruction in Gastrointestinal Cancers: Prognosis and Implications for Timing of Palliative Intervention.J Palliat Med20:774-778

86. Kurita Y, Koide T, Watanabe S et al (2013) : Postpyloric decompression tube placement through a gastrostomy for malignant bowel obstruction.BMC Res Notes6:217

87. Gauvin G, Do-Nguyen CC, Lou J et al (2021) : Gastrostomy Tube for Nutrition and Malignant Bowel Obstruction in Patients With Cancer.J19:48-56

88. Aramaki T, Arai Y, Takeuchi Y et al (2020) : A randomized, controlled trial of the efficacy of percutaneous transesophageal gastro-tubing (PTEG) as palliative care for patients with malignant bowel obstruction: the JIVROSG0805 trial.Support Care Cancer28:2563-2569

89. Aramaki T, Arai Y, Inaba Y et al (2013) : Phase Il study of percutaneous transesophageal gastrotubing for patients with malignant gastrointestinal obstruction; JIVROSG-0205.J Vasc Interv Radiol24:1011-7

90. Selby D, Nolen A, Sittambalam C et al (2019) : Percutaneous Transesophageal Gastrostomy (PTEG): A Safe and Well-Tolerated Procedure for Palliation of End-Stage Malignant Bowel Obstruction.J Pain Symptom Manage58:306-310

91. Mackey R, Chand B, Oishi $\mathrm{H}$ et al (2005) : Percutaneous transesophageal gastrostomy tube for decompression of malignant obstruction: report of the first case and our series in the US.J Am Coll Surg201:695-700

92. Ferguson HJ, Ferguson $\mathrm{Cl}$, Speakman J et al (2015) : Management of intestinal obstruction in advanced malignancy.Ann Med Surg (Lond)4:264-70

93. Paul Olson TJ, Pinkerton C, Brasel KJ et al (2014) : Palliative surgery for malignant bowel obstruction from carcinomatosis: a systematic review.JAMA Surg149:383-92

94. Adler DG (2005) : Management of Malignant Colonic Obstruction.Curr Treat Options Gastroenterol8:231-237

95. Van Hooft JE, Van Halsema EE, Vanbiervliet $G$ et al Self-expandable metal stents for obstructing colonic and extracolonic cancer: European Society of Gastrointestinal Endoscopy (ESGE) Clinical Guideline.Gastrointestinal Endoscopy80:747-761.e7, 2014

96. Wang FG, Bai RX, Yan M et al (2020) : Short-Term Outcomes of Self-Expandable Metallic Stent versus Decompression Tube for Malignant Colorectal Obstruction: A Meta-Analysis of Clinical Data.Journal of Investigative Surgery33:762-770

97. Atukorale YN, Church JL, Hoggan BL et al (2016) : Self-Expanding Metallic Stents for the Management of Emergency Malignant Large Bowel Obstruction: a Systematic Review.J Gastrointest Surg20:455-62

98. Cennamo V, Luigiano C, Coccolini F et al (2013) : Meta-analysis of randomized trials comparing endoscopic stenting and surgical decompression for colorectal cancer obstruction. International Journal of Colorectal Disease28:855-863 
99. Jain SR, Yaow CYL, Ng CH et al (2020) : Comparison of colonic stents, stomas and resection for obstructive left colon cancer: a meta-analysis.Tech Coloproctol24:1121-1136

100. Khot UP, Lang AW, Murali K et al (2002) : Systematic review of the efficacy and safety of colorectal stents.Br J Surg89:1096-102

101. Neo VSQ, Jain SR, Yeo JW et al (2021) : Controversies of colonic stenting in obstructive left colorectal cancer: a critical analysis with meta-analysis and meta-regression.Int $\mathrm{J}$ Colorectal Dis36:689-700

102. Watt AM, Faragher IG, Griffin TT et al (2007) : Self-expanding metallic stents for relieving malignant colorectal obstruction: a systematic review.Ann Surg246:24-30

103. Veld J, Umans D, van Halsema E et al (2020) : Self-expandable metal stent (SEMS) placement or emergency surgery as palliative treatment for obstructive colorectal cancer: A systematic review and meta-analysis.Critical Reviews in Oncology/Hematology 155 (no pagination),

104. Ribeiro IB, Bernardo WM, Martins BDC et al (2018) : Colonic stent versus emergency surgery as treatment of malignant colonic obstruction in the palliative setting: a systematic review and metaanalysis.Endosc Int Open6:E558-E567

105. Young CJ, Zahid A (2018) : Randomized controlled trial of colonic stent insertion in non-curable large bowel obstruction: a post hoc cost analysis.Colorectal Dis20:288-295

106. Banting SP, Waters PS, Peacock $O$ et al (2021) : Management of primary and metastatic malignant small bowel obstruction, operate or palliate. A systematic review.ANZ J Surg91:282-290

107. Gemlo B, Rayner AA, Lewis B et al (1986) : Home support of patients with end-stage malignant bowel obstruction using hydration and venting gastrostomy.Am J Surg152:100-4

108. Bozzetti $F(2019)$ : The role of parenteral nutrition in patients with malignant bowel obstruction.Support Care Cancer27:4393-4399

109. Muscaritoli M, Arends J, Bachmann P et al (2021) : ESPEN practical guideline: Clinical Nutrition in cancer.Clin Nutr40:2898-2913

110. NHS Scotland. Scottish Palliative Care Guidelines. Bowel Obstruction (2020) https://www.palliativecareguidelines.scot.nhs.uk/guidelines/symptom-control/bowelobstruction.aspx Accessed on: 15th July 2021

111. Druml C, Ballmer PE, Druml W et al (2016) : ESPEN guideline on ethical aspects of artificial nutrition and hydration.Clin Nutr35:545-56

112. Vanhauwaert E, Matthys C, Verdonck L et al (2015) : Low-residue and low-fiber diets in gastrointestinal disease management.Adv Nutr6:820-7

113. Bozzetti $F$ (2015) : Nutrition, hydration, and patient's preferences at the end of life.Support Care Cancer23:1487-8

114. Coelho TA, Wainstein AJA, Drummond-Lage AP (2020) : Hypodermoclysis as a Strategy for Patients With End-of-Life Cancer in Home Care Settings.Am J Hosp Palliat Care37:675-682 
115. Good P, Richard R, Syrmis W et al (2014) : Medically assisted hydration for adult palliative care patients.Cochrane Database Syst Rev:Cd006273,

116. Lokker ME, van der Heide A, Oldenmenger WH et al (2021) : Hydration and symptoms in the last days of life.BMJ Support Palliat Care11:335-343

117. Raijmakers NJH, van Zuylen L, Costantini M et al (2011) : Artificial nutrition and hydration in the last week of life in cancer patients. A systematic literature review of practices and effects.Ann Oncol22:1478-1486

118. Bruera E, Hui D, Dalal S et al (2013) : Parenteral hydration in patients with advanced cancer: a multicenter, double-blind, placebo-controlled randomized trial.J Clin Oncol31:111-8

119. Dreesen M, Foulon V, Spriet I et al (2013) : Epidemiology of catheter-related infections in adult patients receiving home parenteral nutrition: a systematic review.Clin Nutr32:16-26

120. Pittiruti M, Hamilton H, Biffi R et al (2009) : ESPEN Guidelines on Parenteral Nutrition: central venous catheters (access, care, diagnosis and therapy of complications).Clin Nutr28:365-77

121. Sowerbutts AM, Lal S, Sremanakova J et al (2018) : Home parenteral nutrition for people with inoperable malignant bowel obstruction.Cochrane Database Syst Rev8:CD012812

122. Bozzetti F, Cozzaglio L, Biganzoli E et al (2002) : Quality of life and length of survival in advanced cancer patients on home parenteral nutrition.Clin Nutr21:281-8

123. Cotogni P, De Carli L, Passera R et al (2017) : Longitudinal study of quality of life in advanced cancer patients on home parenteral nutrition.Cancer Med6:1799-1806

124. Finocchiaro C, Gervasio S, Agnello E et al (2002) : Multicentric study on home parenteral nutrition in advanced cancer patients. Rivista italiana di nutrizione parenterale ed enterale20:98-107

125. Naghibi M, Smith TR, Elia M (2015) : A systematic review with meta-analysis of survival, quality of life and cost-effectiveness of home parenteral nutrition in patients with inoperable malignant bowel obstruction.Clin Nutr34:825-37

126. Bozzetti F, Cotogni P, Lo Vullo S et al (2015) : Development and validation of a nomogram to predict survival in incurable cachectic cancer patients on home parenteral nutrition.Ann Oncol26:2335-40

127. Messing B, Lémann M, Landais $P$ et al (1995) : Prognosis of patients with nonmalignant chronic intestinal failure receiving long-term home parenteral nutrition.Gastroenterology 108:1005-10

128. Ruggeri E, Giannantonio M, Agostini F et al (2020) : Home artificial nutrition in palliative care cancer patients: Impact on survival and performance status.Clin Nutr39:3346-3353

129. Brard L, Weitzen S, Strubel-Lagan SL et al (2006): The effect of total parenteral nutrition on the survival of terminally ill ovarian cancer patients.Gynecol Oncol103:176-80

130. Chouhan J, Gupta R, Ensor J et al (2016) : Retrospective analysis of systemic chemotherapy and total parenteral nutrition for the treatment of malignant small bowel obstruction.Cancer Med5:23947

131. Santarpia L, Alfonsi L, Pasanisi F et al (2006) : Predictive factors of survival in patients with peritoneal carcinomatosis on home parenteral nutrition.Nutrition22:355-60 
132. Dzierzanowski T, Sobocki J (2021) : Survival of patients with multi-level malignant bowel obstruction on total parenteral nutrition at home.Nutrients13:1-12

133. Jairam V, Lee V, Park HS et al (2019) : Treatment-Related Complications of Systemic Therapy and Radiotherapy.JAMA Oncol5:1028-1035

134. Shim J, Seo TS, Song MG et al (2014) : Incidence and risk factors of infectious complications related to implantable venous-access ports.Korean J Radiol15:494-500

135. Niedzwiedz CL, Knifton L, Robb KA et al (2019) : Depression and anxiety among people living with and beyond cancer: a growing clinical and research priority.BMC Cancer19:943

136. Krebber AM, Buffart LM, Kleijn G et al (2014) : Prevalence of depression in cancer patients: a metaanalysis of diagnostic interviews and self-report instruments.Psychooncology23:121-30

137. Caillet P, Liuu E, Raynaud Simon A et al (2017) : Association between cachexia, chemotherapy and outcomes in older cancer patients: A systematic review.Clin Nutr36:1473-1482

138. Ni J, Zhang L (2020) : Cancer Cachexia: Definition, Staging, and Emerging Treatments.Cancer Manag Res12:5597-5605

139. Vachon ML, Kristjanson L, Higginson I (1995) : Psychosocial issues in palliative care: the patient, the family, and the process and outcome of care.J Pain Symptom Manage10:142-50

140. Möllerberg ML, Årestedt K, Sandgren A et al (2020) : Adaptation and psychometric evaluation of the short version of Family Sense of Coherence Scale in a sample of persons with cancer in the palliative stage and their family members.Palliat Support Care18:24-32

141. Daines P, Stilos K, Moura S et al (2013) : Nurses' experiences caring for patients and families dealing with malignant bowel obstruction.Int J Palliat Nurs19:593-8

142. Platt V (2001) : Malignant bowel obstruction: so much more than symptom control.Int J Palliat Nurs7:547-54

143. Chase DM, Monk BJ, Wenzel LB et al (2008) : Supportive care for women with gynecologic cancers.Expert Rev Anticancer Ther8:227-41

144. Cusimano MC, Sajewycz K, Nelson M et al (2020) : Supported self-management as a model for endof-life care in the setting of malignant bowel obstruction: A qualitative study.Gynecol Oncol157:745753

145. Hoppenot C, Hlubocky FJ, Chor J et al (2020) : Approach to Palliative Care Consultation for Patients With Malignant Bowel Obstruction in Gynecologic Oncology: A Qualitative Analysis of Physician Perspectives.JCO Oncol Pract16:483-489

146. Fallon EA, Miner TJ (2020) : Malignant Bowel Obstruction in the Time of the COVID-19 Pandemic.Am Surg86:1473-1477

\section{Tables}

\section{Table 1}




\section{Level Criteria}

I Evidence obtained from meta-analysis of multiple, well-designed, controlled studies; randomized trials with low false-positive and false-negative errors (high power).

II $\quad$ Evidence obtained from at least one-well designed experimental study; randomized trials with high false-positive and/or false-negative errors (low power).

III Evidence obtained from well-designed, quasi-experimental studies, such as nonrandomized, controlled single-group, pretest-posttest comparison, cohort, time, or matched case-control series.

IV Evidence obtained from well-designed, non-experimental studies, such as comparative and correlational descriptive and case studies.

V Evidence obtained from case reports and clinical examples.

Adapted from: MASCC. (2018). MASCC Guidelines Policy: Recommendations for MASCC Guideline Construction and the Endorsement of Externally Generated Guidelines.

https://www.mascc.org/assets/Toolbox/PoliciesForms/mascc_guideline_policy_2018.pdf

\section{Table 2}

MASCC Grading of Recommendations

\section{Grade Evidence needed}

A Evidence of type I or consistent findings from multiple studies of type II,

III, or IV.

B Evidence of types II, III, or IV and findings are generally consistent.

C Evidence of types II, III, or IV and findings are inconsistent.

D Little or no systematic empirical evidence.

Adapted from: MASCC. (2018). MASCC Guidelines Policy: Recommendations for MASCC Guideline Construction and the Endorsement of Externally Generated Guidelines.

https://www.mascc.org/assets/Toolbox/PoliciesForms/mascc_guideline_policy_2018.pdf

\section{Figures}


A

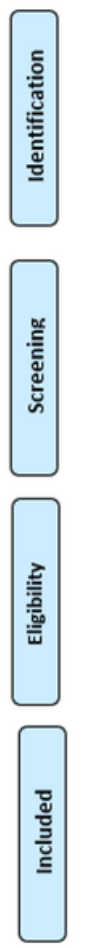

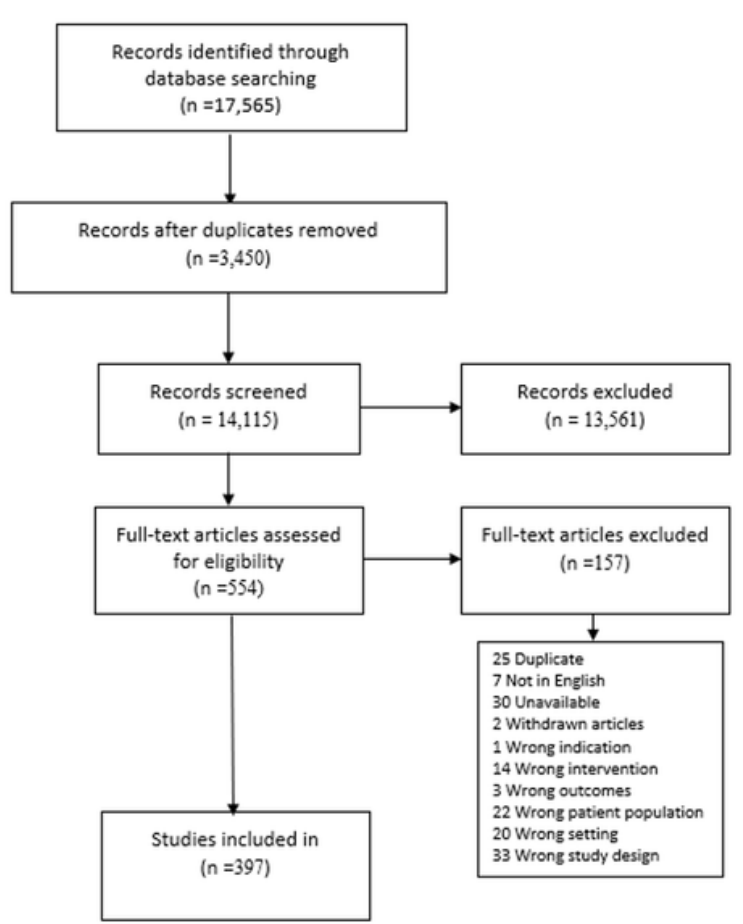

B

\begin{tabular}{|l|r|}
\hline Database & Total retrieved \\
\hline $\begin{array}{l}\text { Medline ALL 1946 to March 23, } \\
2021\end{array}$ & 4906 \\
\hline $\begin{array}{l}\text { Embase Classic +Embase 1947 to } \\
2021 \text { March 23 }\end{array}$ \\
\hline $\begin{array}{l}\text { Cochrane Central Register of } \\
\text { Controlled Trial March 23, 2021 }\end{array}$ \\
\hline $\begin{array}{l}\text { Cochrane Database of Systematic } \\
\text { Reviews March 23, 2021 }\end{array}$ \\
\hline $\begin{array}{l}\text { Psyclnfo 1806 to March Week 3 } \\
2021\end{array}$ \\
\hline $\begin{array}{l}\text { Scopus from Elsevier March 25, } \\
2021\end{array}$ \\
\hline GIM from WHO March 25, 2021 \\
\end{tabular}

Figure 1

PRISMA flow diagram (A) and chart numbers (B).

\section{Supplementary Files}

This is a list of supplementary files associated with this preprint. Click to download.

- MASCCguidelineAppendix11Nov.docx 